\title{
Cloning, Sequence Analysis and Expression Patterns during Seed Germination of a Rapeseed (Brassica napus $\mathrm{L}$.) G-x-S-x-G-motif Lipase Gene
}

\section{Imen GLAIED GHRAM ${ }^{1}$, Hatem BELGUITH ${ }^{1}$, Maha BEN MUSTAPHA ${ }^{2}$, Issam HIMILA ${ }^{3}$, Balkiss BOUHAOUALA ${ }^{3}$, Oscar VICENTE ${ }^{4 *}$, Jeannette BEN HAMIDA ${ }^{1}$}

\author{
${ }^{1}$ Unité Protéomie Fonctionnelle et Potentiel Nutraceutique de la Biodiversité de Tunisie, Institut des Sciences Biologiques Appliquées de Tunis, \\ Université de Tunis El Manar \\ ${ }^{2}$ Biochemistry and Molecular Biology Laboratory (03/UR/0902), Faculty of Sciences of Bizerte, University of Carthage, \\ Tunisia \& Laboratory of Protein Engineering and Bioactive Molecules (LIP-MB), \\ National Institute of Applied Sciences and Technology (INSAT), University of Carthage, Tunisia \\ ${ }^{3}$ Laboratoire des Venins et Molécules Thérapeutiques, Université de Tunis El Manar, Institut Pasteur de Tunis, \\ 13 Place Pasteur BP74, 1002 Tunis Belvedere, Tunisia \\ ${ }^{4}$ Instituto de Biología Molecular y Celular de Plantas (UPV-CSIC), Universitat Politècnica de Valéncia, \\ Spain; ovicente@ibmcp.upv.es (correspondingauthor)
}

\begin{abstract}
Lipases catalyze the hydrolysis of ester bonds in triacylglycerides, generating glycerol and free fatty acids. These enzymes are encoded by extremely complex gene families, and appear to fulfil many different biological functions. Although they are present in all types of organisms, available information on plant lipases is still very limited, as compared to their bacterial and animal counterparts. A full-length clone, BnLIP, encoding a putative lipase, has been isolated by PCR amplification of Brassica napus genomic DNA, with oligonucleotide primers derived from the sequence of an Arabidopsis thaliana homologue. The clone included an open reading frame of $1581 \mathrm{bp}$ encoding a polypeptide of 526 amino acids, with a calculated molecular mass of $59.5 \mathrm{kDa}$. Analysis of the deduced protein sequence, sequence alignment with homologous proteins from related plant species, and a phylogenetic analysis revealed that the BnLIP protein belongs to the 'classical' GxSxG-motif lipase family. RTPCR assays indicated that the $B n L I P$ gene is expressed specifically, but only transiently, during seed germination: the lipase mRNA was not present at detectable levels in ungerminated seeds, was detected only three days after seed imbibition, but its levels decreased rapidly afterwards. No expression was observed in roots, stems or leaves of adult plants. This expression pattern suggests that BnLIP is one of the lipases involved in the hydrolysis of triacylglycerides stored in rapeseed seeds, ultimately providing nutrients and energy to sustain seedling growth until photosynthesis is activated.
\end{abstract}

Keywords: GDSL lipases, GxSxG lipases, gene expression, seed germination, RT-PCR, triacylglycerolacylhydrolases

\section{Introduction}

Lipases (triacylglycerolacylhydrolases, EC 3.1.1.3) are enzymes that catalyze the hydrolysis of ester bonds in triacylglycerides (TAGs), to generate glycerol and free fatty acids. They are adapted to operate at the interfaces of biphasic systems, a phenomenon known as 'interfacial activation', in which the characteristic substrate is an aggregate, micelles or monomolecular films formed by ester molecules, interfacing an aqueous medium (Santos et al., 2013). In many lipases, a flexible hydrophobic 'lid' formed by an $\alpha$-helix stretch covers the active site, which is released upon adsorption of the enzyme to the interface, thus allowing the access of the substrate (Quettier and Eastmond, 2009). Lipases have been isolated from various sources: bacteria, fungi, animals, plants, or algae. Although some lipases have been purified from seeds of different species (e.g. Lin and Huang, 1984; Fuchs et al. 1996), very few have been characterised at the molecular level, mainly due to their generally low contents in the reported tissues, and the loss of activity when traditional purification strategies are employed (Seth et al., 2014). Therefore, information on plant lipases is still limited, especially when compared with the mammalian and bacterial counterparts. 
438

Seed germination, a complex and multistage process, is a critical developmental stage in the life cycle of seed plants. During germination and cotyledon senescence, oil bodies are degraded by lipases, which mobilize stored TAGs (Vijayakumar and Gowda, 2012). It has been reported that, with a few exceptions, lipase activity is absent in ungerminated (or dormant) seeds and increases rapidly upon germination (e.g., Peres Polizelli et al., 2008). In some cases, enzymes isolated from dormant seeds - for example from castor bean (Estamond, 2004), peanut (Sanders and Pattee, 1975), or Jatropha curcas (Abigor et al., 2002) - are highly active in vitro but apparently inactive in vivo. Oilseed lipases have attracted much interest because of their great potential for commercial exploitation as industrial enzymes, including those isolated from oilseed species that can be considered as underutilized (Enujiugha et al., 2004). These enzymes are effective catalysts of various inter-esterification and trans-esterification reactions (Gupta et al., 2004; Romdhane et al. 2012) in the presence of decreasing amounts of water and often in the presence of organic solvents (Ogino et al., 2004; Palacios et al., 2014). Because of their versatility, lipases are the enzymes of choice for multiple applications in different fields: food, pharmaceutical, chemical, detergent, leather, textile, cosmetics and paper industries, for organic synthesis, biodiesel production or even environmental management (Pandey et al., 1999; Sharma et al., 2002; Barros et al., 2010; Foresti and Ferreira, 2010).

According to characteristic conserved sequence elements, lipases can be divided into GxSxG and GDSL families. The GxSxG lipases are the so-called 'classical' lipases, and their active site is a catalytic Ser, His, Asp/Glu triad; the serine residue is located in a highly conserved Gly-X-Ser-X-Gly motif (X can be any amino acid, and sometimes the first Gly is replaced with $\mathrm{Ala})$, located near the centre of the protein, in a turn between an $\alpha / \beta$-strand and an $\alpha$-helix - a so-called nucleophilic elbow and some additional conserved consensus sequences (Woolley et al., 1994); apart from these conserved elements, there is little overall sequence similarity between family members. Without such nucleophilic elbow present in the classical lipases, GDSL lipases have a serine-containing motif (the GDSL motif) closer to the N-terminus, including the Ser of the catalytic triad (Ser, Asp, His). GDSL lipases do not have significant sequence homology to classical lipases, and show properties such as broad substrate specificity and regiospecificity (Akoh et al., 2004; Ling et al., 2006).

The seeds of Brassica napus (rapeseed) are rich in oil, with a high proportion of mono and polyunsaturated fatty acids, such as oleic and linoleic acids, and very low content of saturated fat. This plant is one of the main sources of edible oil for humans (Niu et al., 2009), as rapeseed is among the most important oilseed crops worldwide. Large amounts of TGAs are stored in seeds, and during seed germination lipases turn active and catalyse the breakdown of lipids for sustaining post-germinative growth. To understand the molecular mechanisms underlying these biological processes, it is necessary to characterise the lipases involved. Based on the homology with a lipase gene from the model plant Arabidopsis thaliana, we isolated a Brassica napus gene encoding a $\mathrm{GxSxG}$ lipase, determined its genomic structure and analyzed its expression patterns in several plant organs and during seed germination.

\section{Materials and Methods}

\section{Plantmaterial}

Oilseed rape (Brassica napus L. var. 'Pactol') seeds were soaked in tap water for $24 \mathrm{~h}$, sterilised with a $7 \%$ (v/v) aqueous solution of calcium hypochlorite for $5 \mathrm{~min}$, thoroughly washed, and germinated in the dark at $26^{\circ} \mathrm{C}$, on filter paper moistened with distilled water. Etiolated seedlings, collected at different times after germination, as well as roots, stems, leaves and flowers harvested from adult plants in a local farm were used for RNA extraction, to analyze the expression of the lipase gene.

\section{Plasmids and bacterialstrains}

PCR amplification products were cloned in plasmid pGEM T-easy (Promega), following the protocol recommended by the company. Escherichia coli $\mathrm{DH} 5 \alpha$ cells were used as host in all cloning procedures.

\section{DNA}

Isolation of the lipase gene BnLIP, from Brassica napus genomic

Rapeseed genomic DNA was isolated from old etiolated seedlings, using the 'DNA purification kit' (Promega). A DNA fragment including the lipase gene was amplified by PCR, with primers designed from the genomic sequence of an Arabidopsis thaliana homologue (GeneBank accession number NM112294.4) (forward primer sequence: 5'ATGCACAAAGACAACGATTCGGGTT-3', reverse primer sequence: 5'-ATTATCGGGTCCAAGCCTAAC$\left.3^{\prime}\right)$. The PCR reaction mixture contained, in a total volume of $50 \mu \mathrm{l}, 2 \mu \mathrm{l}$ of $B$. napus genomic DNA, the four dNTPs (200 $\mu \mathrm{M}$ each), $2.4 \mathrm{mM} \mathrm{MgCl}_{2}, 5 \mu \mathrm{l}$ of each primer $(1 \mu \mathrm{M}$ final concentration), 1 unit of GoTaq Flexi DNA polymerase, and reaction buffer (Promega). The PCR program included an initial denaturing step at $94^{\circ} \mathrm{C}$ for $2 \mathrm{~min}, 35$ cycles of amplification (denaturing for $30 \mathrm{~s}$ at $94^{\circ} \mathrm{C}$, primer annealing for $30 \mathrm{~s}$ at $55^{\circ} \mathrm{C}$, and $2 \mathrm{~min}$ extension at $72^{\circ} \mathrm{C}$ ), and a final extension at $72^{\circ} \mathrm{C}$ for $10 \mathrm{~min}$. The PCR amplified products were cloned into pGEM T-easy vector and sequenced using M13 forward and reverse primers.

\section{Reverse transcription (RT)-PCR}

Total RNA was extracted from etiolated oilseed rape seedlings, at different days after germination (DAG), and from different adult plant organs (roots, stems, leaves, and flowers) using TRIZOL reagent (Thermo Fisher Scientific) and the protocol provided by the manufacturer. After treating the RNA preparations with RNase-free DNase, the first-strand cDNA was synthesized using the Super-script II kit (Invitrogen). PCR amplification was performed with primers designed from the coding region of the gene (forward primer: 5'-CAAGTTTGTAGTCACGGGTCACAG-3' and reverse primer: 5'-CGTAAGGCAATCTCGGGACAAG-3'), which should amplify a fragment of 239 bp of the cDNA. The reaction mixture included $4 \mu$ of the previous RT reaction; the other components of the PCR reaction, and the amplification conditions, were the same that those described in the previous section for amplification of genomic DNA. As an internal control, the mRNA of the rapeseed actin gene, BnACT (Genebank accession AF111812), was detected by RT-PCR of the same total RNA samples, with the forward primer Fw973 
(5'-TTCCCTGGAATTGCTGACCG-3') and the reverse primer Rv1052 (5'-ACTGTACTTCCTCTCAGGCG-3'), which amplify a $99 \mathrm{bp}$ fragment of the actin cDNA.

\section{Sequence analysis and bioinformatics}

Programs accessed at the US National Center for Biotechnology Information (NCBI) were used for nucleotide sequence analysis, deduction of the amino acid sequences and database searches. Genes encoding several plant lipases were retrieved from the GenBank database by BLAST searches and used for sequence comparison. Protein sequences were aligned using the Clustal X 1.8 programme.

The phylogenetic tree was produced by neighbour-joining (NJ) methods (Kimura 2-parameter model, 10,000 replicates, bootstrap phylogeny test) based on lipase amino acid sequences, using MEGA software version 4.0.

\section{Results}

\section{Isolation of an oilseed rape lipase gene, BnLIP}

In previous experiments, a 582 bp DNA fragment was amplified by PCR from rapeseed seedlings DNA, using primers designed from the conserved catalytic core sequence of lipases from several plant species (Gladied Ghram et al. 2013). BLAST searches showed that this fragment shared $85 \%$ homology, at the nucleotide level, with sequences in an Arabidopsis thaliana gene (GeneBank accession $\mathrm{n}^{\circ}$ NM112294.4), encoding a putative $\alpha / \beta$-acylhydrolase-lipase protein. The deduced amino acid sequence contained the conserved domains characteristic of GxSxG-type lipases, thus confirming the isolation of partial clone of a $B$. napus 'classical' lipase gene. New primers were designed from the $A$. thaliana gene, to isolate by PCR the full-length rapeseed clone from $B$. napus genomic DNA. A 1,841 bp fragment was amplified, cloned and sequenced. The sequence has been deposited in the GeneBank database (Accession nº KR998334).

\section{Structure of the genomic clone}

An alignment of the $B$. napus genomic sequence with the $A$. thaliana homologue allowed determining the structure of the gen, since the number and position of intervening sequences were found to be conserved between the two genes. BnLIP contained five exons and four introns, sequentially located at the nucleotide positions 162, 690, 799 and 1500, respectively; the introns of the rapeseed gene were generally shorter than the corresponding introns of Arabidopsis. Fig. 1 shows a schematic representation of the BnLIP structure in the region including the ORF (that is, in between the translation start and stop codons), with the position and size of each exon and intron.

\section{DNA and protein sequence analysis}

The cDNA sequence of BnLIP, obtained from the genomic clone by eliminating the introns and joining the coding sequences (Fig. 1), and the deduced amino acid sequence, are shown in Fig. 2. The ATG initiation codon is located at position 261 and a stop codon, TGA, at position 1,841 of the DNA sequence. The cDNA contains, therefore, an open reading frame (ORF) of $1,581 \mathrm{bp}$ (including the stop codon), encoding a putative protein of 526 amino acids (Fig. 2). The protein has a calculated molecular mass of $59.5 \mathrm{kDa}$, and a predicted isoelectric point of 5.7.

In the amino acid sequence, the conserved GxSxG motif characteristic of 'classical' lipases (G-H-S-L-G, in this case) is located at position 317. Apart from the serine residue within this motif, the other members of the catalytic triad characteristic of all true lipases can be found at positions 407 (Asp) and 475 (His) in the amino acid sequence (Fig. 2).

Protein BLAST searches detected several sequences in the databases with significant homology to the newly described Brassica napus lipase, most of them putative or not yet characterized proteins; some of these sequences have been aligned and are shown in Fig. 3. One of the proteins with highest homology (about 54\% identical amino acids, and 60\% similarity) is a putative GxSxG-motif lipase from a closely related species of the same genus, Brassica rapa (GeneBank accession $\mathrm{n}^{\circ} \mathrm{XM}$ 009148129.1); it should be mentioned that a similar degree of sequence homology has been found with some other B. napus protein sequences (not included in the alignment of Fig. 3). Other putative lipases from species belonging to the Brassicaceae (Eutrema salsugineum, Camelina sativa, Capsella rubella, Arabidopsis thaliana) or the related family Cleomaceae (Tarenaya hassleriana), showed somewhat

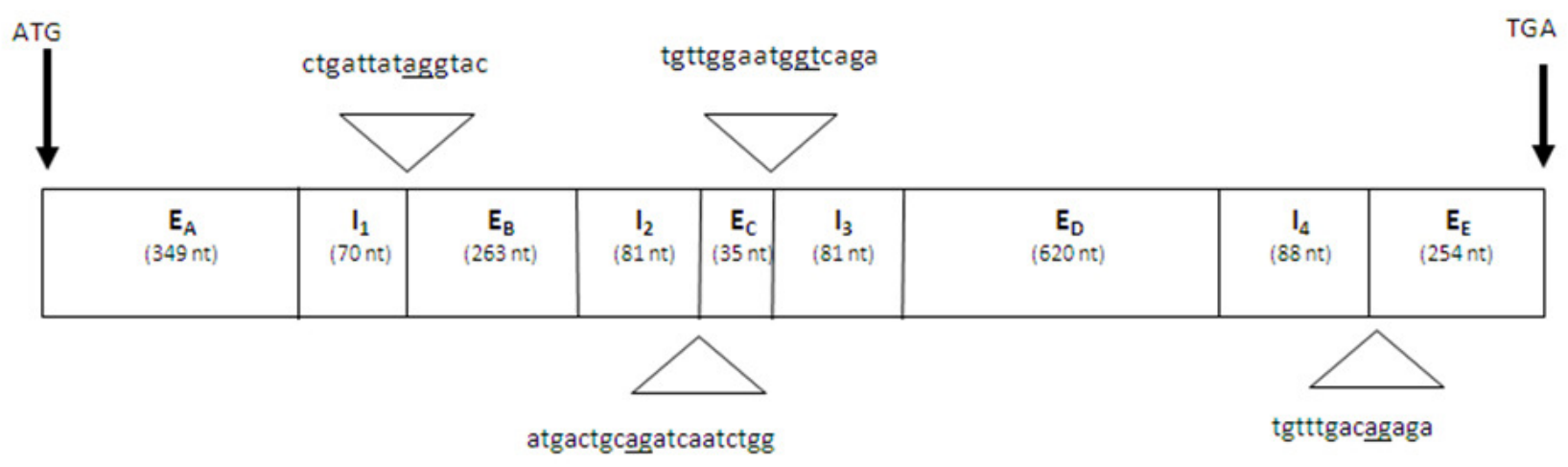

Fig. 1. Schematic representation of the exon-intron organization of the BnLIP gene. Exons are marked as $E_{A}, E_{B}, E_{C}, E_{D}$ and $E_{E}$, and introns are numbered as $\mathrm{I}_{1}, \mathrm{I}_{2}, \mathrm{I}_{3}$, and $\mathrm{I}_{4}$. The initial codon ATG and terminal codon TGA are marked with arrows, the lengths of exons and introns are indicated within the corresponding boxes. For some of the boundaries between exons and introns, the flanking sequences are shown, with the conserved splice sites (GT, AG) underlined 
atgcacaaccccacgattcgggttcgaatccgggccccaggtcaaactacttgatcgttcgg cctcaccgaggtggctacagagacctttttcaatacggtgtgagaggagacgaalctagc aaaa caagt tcctcgaacgacctgatgatcactccgacaggaccacatcggcgatcaat gtacaagccggtgatcaccgatgggtcatcgtggtctcgatcctcgtccgcaagatcatc grgcttctccgaacaccgatggaatacacgggtt gigtcgttgactttgtgctcaatctc

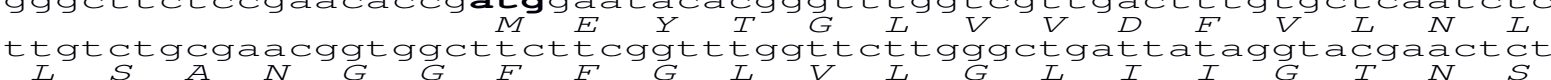

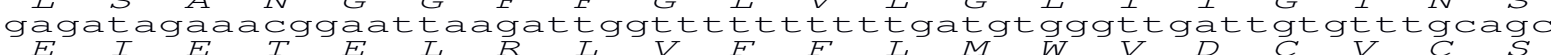
gaaggtagtggtaccagagagaggctctgtgggatt t

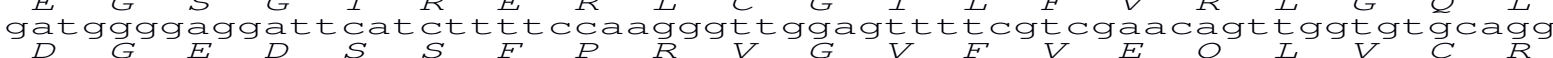

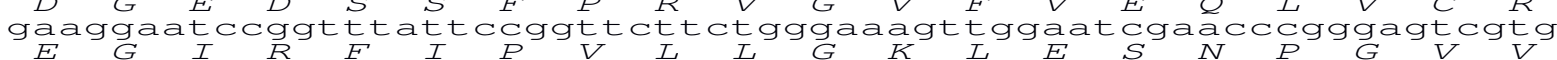

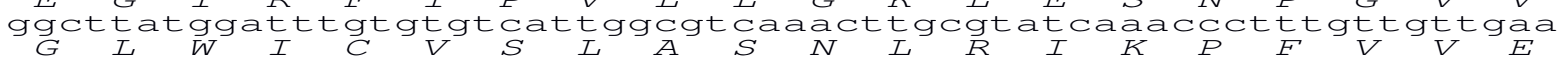

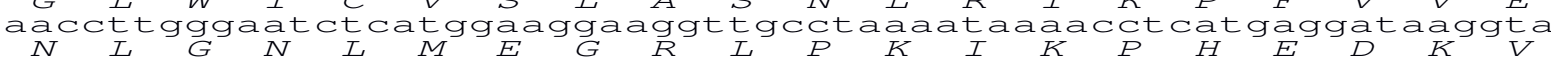

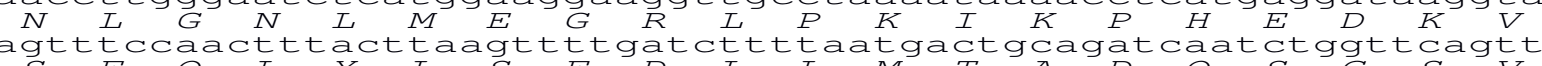
agtttccaactetacttaagttetgatctettaatgactgcagatcaatctggttcagtt

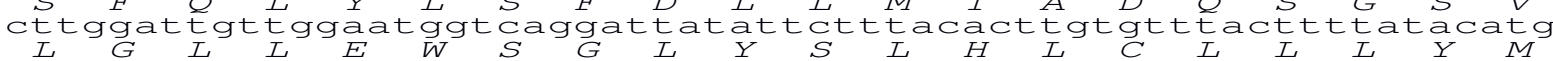

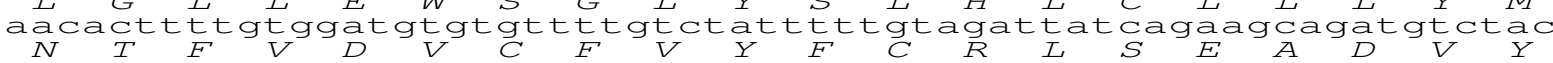

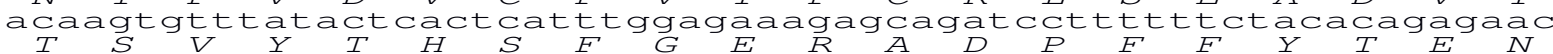

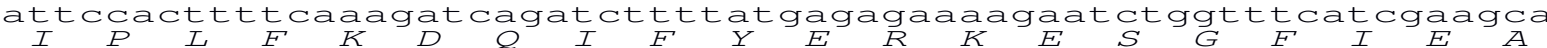

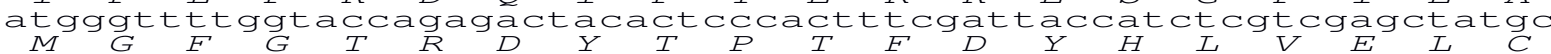

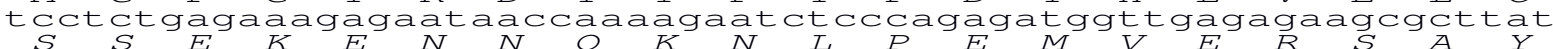
tacgcagttagagaaactctgtatcgtt tgcttgrggagcacgcaaacgccaagttegt gtcacgggtcacagct grgaggcgcgtttgcgattctgtttcccacgttgctggtgttc

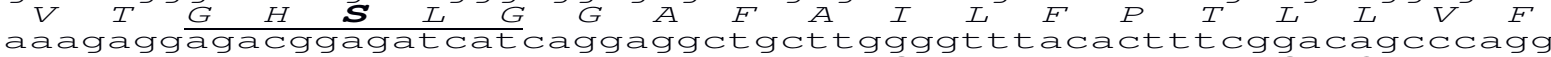

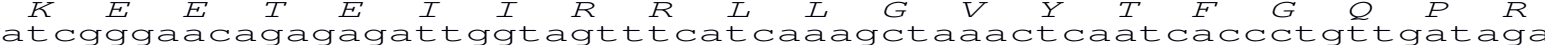

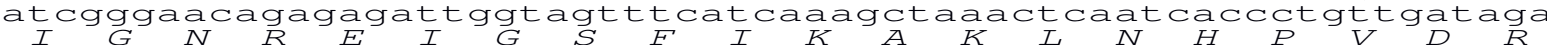

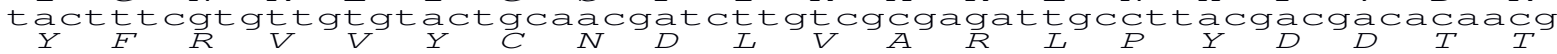

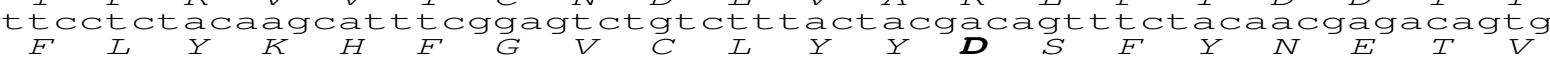

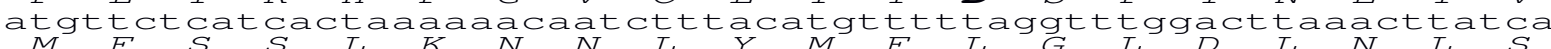

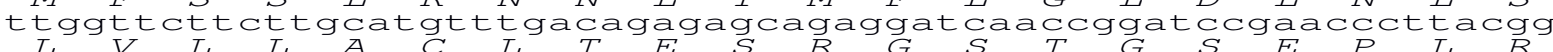

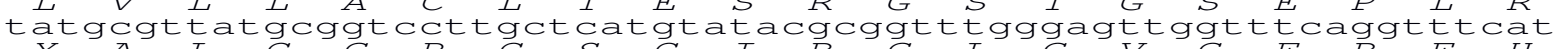
catggggttcatt tatggaccgggttattcagaaggatggttttggatct

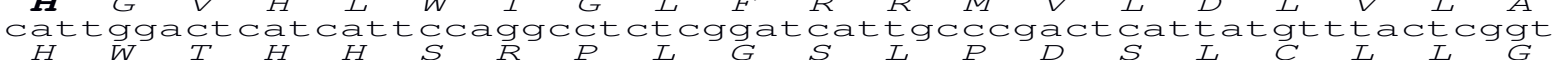
$H$
ttggctggaccogatattattcacttgtcoattgcttga

$I \quad A \quad G \quad P$ D I I $H$ I I S I A

Fig. 2. The cDNA nucleotide sequence (deduced from the genomic sequence by elimination of intron sequences), and the corresponding amino acid sequence of BnLIP from Brassica napus (GenBank accession $n^{\circ}$ KR998334). The translation initiation codon (ATG) and the stop codon (TGA) are shown in boldface. The GxSxG-motif is underlined (GHSLG), and the catalytic triad amino acids $(\mathrm{S}, \mathrm{D}, \mathrm{H})$ are typed in bold letters

lower homology to BnLIP (45-50\% identity, $55-60 \%$ similarity) or shorter overlapping regions (Fig. 3). For comparison, two GDSL-motif lipases from $A$. thaliana have been included in the alignment, 'LTL 1' (Li-tolerant lipase 1) and a 'GDSL-motif lipase/hydrolase-like protein'. These latter proteins are quite different in their sequences from the previously mentioned GxSxG-motif lipases, and do not share many of their conserved amino acids, as it can be clearly seen in Fig. 3. Other lipases or lipase-like proteins from other plant species less related taxonomically, such as Oryza brachyantha (accession $\mathrm{n}^{\circ}$ XP 006649076.1) or Phoenix dactylifera (XP 008778984.1), also showed lower homology to the rapeseed lipase, below 30\% amino acid identity (data not shown). Lipases or lipase-related proteins from animals and microbes were not found to share significant sequence homology with the BnLIP protein.

The alignment of the amino acid sequences of BnLIP and homologous GxSxG-motif lipases allowed detecting the features that define this protein family. First, obviously, the motif that gives name to this group of lipases, which is identical (GHSLG) in the seven members included in the alignment, probably reflecting their taxonomic closeness; this motif is located at position 376, according to the numbering of Fig. 3. As expected, this motif is not present in the two GDSL lipases (Fig. 3). In addition, another four consensus sequences characteristic of the GxSxG lipase family: GGALA, LFP, YTFGQPRI and KHFG were found in the sequences, at locations 380, 386, 407 and 457, respectively. Here again, these consensus amino acids are not present in the sequences of the GDSL lipases (Fig. 3). Concerning the catalytic triad essential for most serine hydrolases (Ollis et al., 1992), in addition to the serine residue within the GHSLG consensus, the other members could be found at positions D466 and H535. Since this catalytic triad (Ser, His and Asp/Glu) is a conserved feature of the wider super-family of $\alpha / \beta$-fold hydrolases, these amino acids are also conserved, in the same positions, in the sequences of the GDSL lipases included in the alignment. 


\section{Phylogenetic analysis}

A phylogenetic analysis, using neighbour-joining methods, was carried out with the amino acid sequences of BnLIP and 13 additional putative GxSxG-lipases from seven different species; for comparison, two Arabidopsis thaliana GDSL-motif lipases were also included in the analysis (Fig. 4). These proteins are the same shown in the multiple alignment of Fig. 3, plus seven additional related sequences, all from species belonging to the Brassicaceae family - except that from Tarenaya hassleriana. The phylogenetic relationships of the GxSxG lipases revealed by this study confirmed the results of the multiple alignment and roughly correlated with the established taxonomic classification of the included species. On the other hand, the two GDSL lipases appear clearly separated from all GxSxG lipases in the phylogenetic tree (Fig. 4).

\section{Gene expression analysis}

RT-PCR, performed on total RNA isolated from germinating rapeseed seeds at different 'days after germination' (DAG), was used to investigate the expression pattern of the $B n L I P$ gene during early seedling development. In imbibed seeds (0 DAG) or at one or two DAG, no transcript could be detected (data not shown). Transcription of the lipase gene seems to be specifically activated at 3 DAG, but only transiently, since the level of the BnLIP mRNA rapidly declined at later times (Fig. 5A). Confirming previous data (Gladied Ghram et al.2013), the expression of the BnLIP gene could not be detected in different organs (roots, stems, leaves or flowers) of adult plants at the reproductive stage (Fig. 5B). The transcript of the housekeeping $B n A C T$ gene, on the contrary, was detected at similar levels in all RNA samples (Fig. 5A, B).

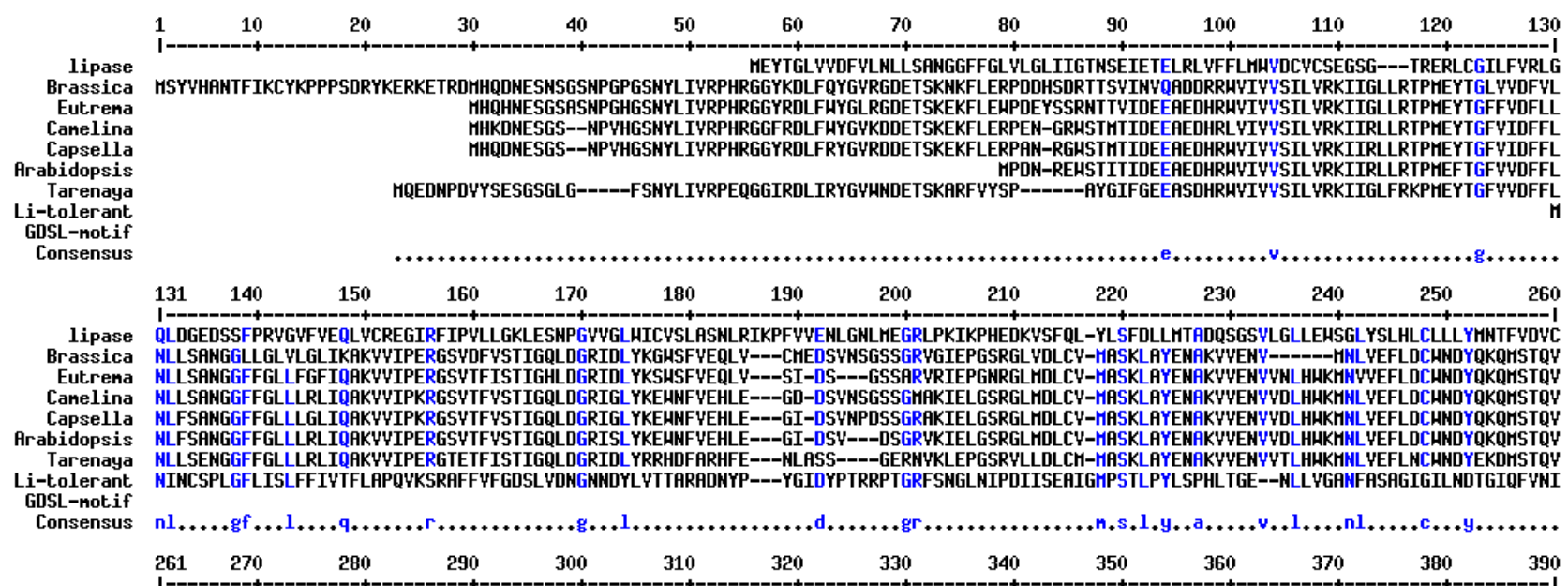

lipase FYYFCRLSEADYYTSYYTHSFGERADPFFYTENIPLFKDQIFYERKESGFIEAMGFGTRDYTPTFDYHLYELCSSEKENHQKNLPEMYERSAYYAYRETLYRLLAEHANAKFYYTGHSLGGAFAILFPTL

Brassica FILTDKEKDADLIL ISFRGTEPFDADDHGTDFDYSHYEIPNY-GKLHMGFIEAMGLGTRDYTPTFHYHLYELNSSEKENNQKNLPEMYERSAYYAYRETLKRLLAEHANAKFYYTGHSLGGALATLFPTL

Eutrena FILTDKQKDANLILISFRGTEPFDADDHGTDFDYSHYEIPNY-GKLHMGFIEAMGLGTRDDTPTFHYHLSDQHSSEEENHKDYLLEMYERSAYYAYRKTLKRLLSEHENAQFYYTGHSLGGALAYLFPTL

Canelina FILTDKEKDANLIVISFRGTEPFDADDHGTDFDYSHYEIPNY-GKLHMGFLEAIGLGNRDDTPTFHYHLFKQTSSEDENNKKKLLDHYERSAYYAYRIILKRLLSEHENAQFYYTGHSLGGALAILFPTL

Capsella FILTDKOKDANLILISFRGTEPFDADDHGTDFDYSHYEIPNY-GKLHMGFLEAMGLGNRDDTPTFHYHLFEHTSSEEDNSKKNLLDYYERSAYYAYRIYLORLLLEHENAOFYYTGHSLGGALATLFPTL

Arabidopsis FYFTDKQKDANLIYISFRGTEPFDADDHGTDFDYSHYEYPNY-GKLHMGFLEAMGLGNRDDTTTFHYNLFEQTSSEEENSKKNHLDHYERSAYYAYRYILKRLLSEHENARFYYTGHSLGGALATLFPTL

Tarenaya FILTDKPKDANLILISFRGTEPFDADDHSTDFDYSHYEIPQL-GRLHMGFIEAHGLGNRNET------LFHETSSE--NPRIIPPDHAKRGAYYSYRRILKRLLQEHGNAEFYYTGHSLGGALAILFPTY

Li-tolerant IRISKQMEYFEQYQLRYSALIGPEATQQLYNQALYLITLGGNDFYNWYYLIPFSARSRQYALPDYYYYLISEYG------KILRKLYELGA----RRYLVTGTGAMGCAPAELAQHSRNGECYGALQTA

GDSL-notif
Consensus f......................ad.....................gfieang.g.r..tp.........sse..n..k.1..n,ergflyy.vr.tl.rll,eh.na,fvvtghslgGa,ailfpT.

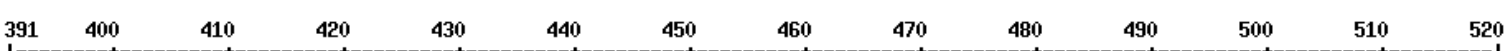

lipase LYFKEETEIIRRLLGYYTFGQPRIGNREIGSFIKAKLNHPYDRYFRYYYCHDLYARLPYDDTTFLYKHFGYCLYYDSFYNETYMFSSLKNHLY-MFLGLDLNLSLYLLACLIESRGSTGSEPLRYALCGP Brassica LYLKEETEMTKRLLGYYTFGQPRIGNREIGSFMKAKLNHPYDRYFRYYYCNDL YPRLPYDDTTFLYKHFGYCLYYDSFYNETRAEDEPDPNPYGMRYAYLAHYNAYHHELYRGLIMGFIYGPGYREGHFRI Eutrena LYLKEETEMTKRLLGYYTFGQPRIGNREYGLFMKDQLNHPYDRYFRYYYCNDLYPRLPYDNNTFLYKHFGLCLYYDSFYNETKAEDEPDPNPYGMRYETLGHYNAYHEL YRGLTMGFIYGPDYKEGHFRI

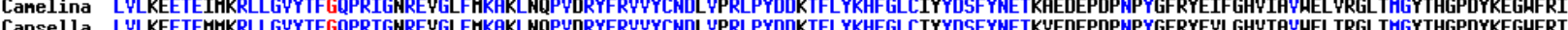

Capsella L

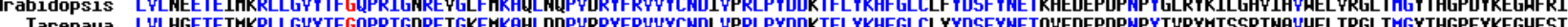

Tarenaya

Li-tolerant

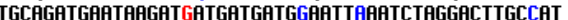

Consensus lvl.,ete...rllgvytfGqprig,re.g.f,ka,l..pv,ryfrvvycnd,v,rlpydd,tflykhf glc..ydsfynet.........n.y............v........ng..............

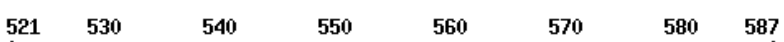

lipase CSCIRGLGY-GFRFHHGYHLHTGLFRRHYLDLYLAHHTHHSRPLGSLPDSLCLLGLAGPDIIHLSIA

Brassica LFRLYGLTIPGLSDHCPTDYYNSYRLGPDYDLQHSPL

Eutrena LFRIMGLFYPGLSDHCTSDYYNSYRLGPDYDLQMSPL

Cansella LFRLMGLLYPGLSDHCPTDYYNSYRLGSDNALQMSPL

Arabidopsis LFRLMGLYIPGLSDHCMTDYYNSYRLGPDNELQMSSL

Tarenaya LLRLMGLYAPGGSAHSPTNYINSYRLGPDSIITHSPL

Li-tolerant

GDSL-notif

Consensus

Fig. 3. Multiple alignment of the amino acid sequences of BnLIP lipase and homologous proteins from other plant species. The proteins included are, in this order: Brassica napus lipase, BnLIP (GeneBank accession KR998334); Brassica rapa uncharacterized X2 (XM_009148128.1); Eutrema salsugineum hypothetical protein (1) (XM_006407026.1); Camelina sativa uncharacterized (XM_010467024.1); Capsella rubella hypothetical protein (XM_006297376.1); Arabidopsis thaliana unknown protein (AY150508.1); Tarenaya hassleriana uncharacterized (XM_010544043.1). Two proteins from A. thaliana, belonging to the GDSL lipases, were also included in the alignment: Li-tolerant lipase 1 (AEE74063.1), and GDSL-motif lipase/hydrolase-like protein (AB022220.1). Conserved residues in the protein catalytic core are coloured in blue, and the four amino acids identical in all nine sequences, in red. Consensus amino acid residues are aligned at the bottom line 


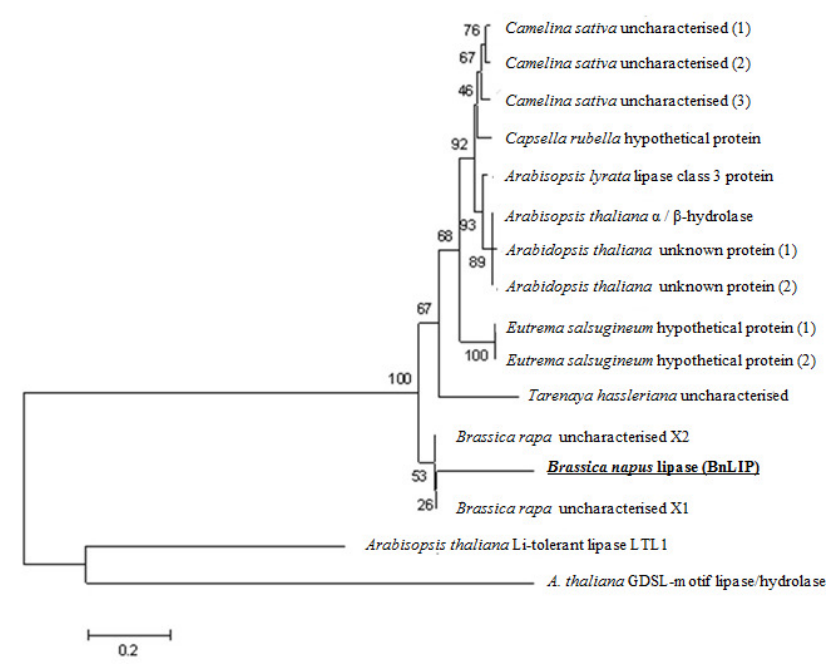

Fig. 4. Phylogenetic relationships of plant lipases. The analysis was performed with Clustal $\mathrm{X}$ and MEGA version 4.0 software, using the neighbour-joining method, and included, in addition to the Brassica napus lipase, BnLIP, (bold and underlined) and all proteins shown in the multiple alignment of Fig. 3, the following protein sequences: Camelina sativa uncharacterized (2) (XM_010503553.1), Camelina sativa uncharacterized (3) (XM_010488931.1), Arabidopsis lyrata subsp. lyrata lipase class 3 family protein (XM_002882830.1), Arabidopsis thaliana alpha/beta-hydrolase (NM_112294.4), Arabidopsis thaliana unknown protein (2) (AY056160.1), Eutrema salsugineum hypothetical protein (XM_006407026.1), and Brassica rapa uncharacterized X1 (XM_009148129.1)

\section{Discussion}

Here, the isolation and initial characterisation of a novel Brassica napus gene encoding a putative lipase protein is reported. Analysis of the deduced amino acid sequence, alignments with homologous proteins from other plant species and a phylogenetic analysis indicated that the putative rapeseed protein, BnLIP, is a member of the 'classical' GxSxG lipase family, containing this highly conserved motif (GHSLG, in this case), as well as the additional consensus sequences characteristic of this class of proteins that distinguish them from the GDSL-motif family (Akoh et al. 2004). Apart from these conserved elements, there is relatively low overall sequence similarity (below 60\%) between BnLip and its homologous $\mathrm{GxSxG}$ lipases, even from closely related species. This is characteristic of these lipolytic enzymes and generally of the wider superfamily of $\alpha / \beta$-fold hydrolases, where protein structures are much more conserved than primary amino acid sequences.

Plants apparently contain a very large number of genes encoding putative lipases belonging to either family, $\mathrm{GxS} \times \mathrm{SG}$ or GDSL. According to these conserved sequence elements, there could be over hundred GDSL-motif lipase homologues in a given plant species, as revealed for example by the Arabidopsis and rice sequencing projects. The huge complexity of this

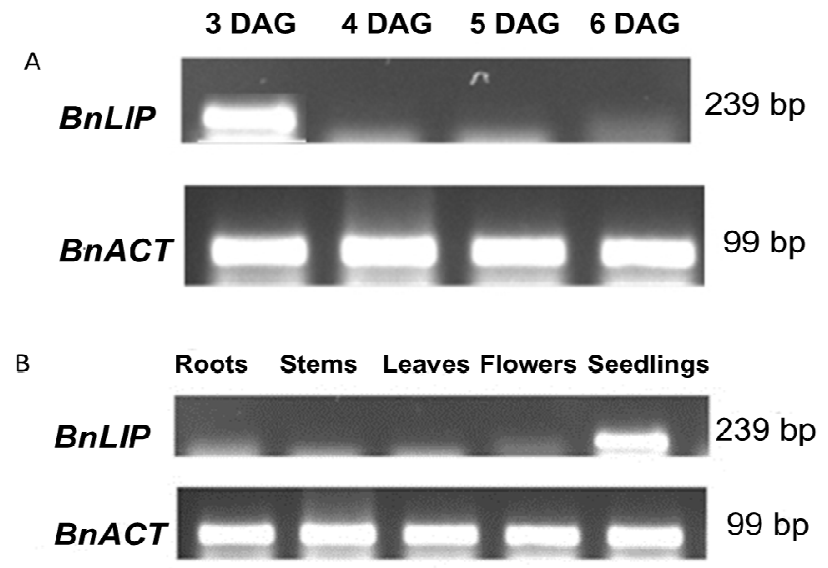

Fig. 5. RT-PCR analysis of BnLIP expression. (A) BnLIP expression profile during seed germination. Total RNA, used as template for the RT-PCR reactions ( $1 \mu \mathrm{g} / \mathrm{sample}$ ), was isolated from early seedlings at 3, 4, 5 and 6 DAG (days after germination). (B) BnLIP expression in rapeseed plants, at the reproductive developmental stage. Total RNA was isolated from the roots, stems, leaves and flowers of adult plants, and from early seedlings (as a positive control), and used in the RTPCR reactions ( $1 \mu \mathrm{g} /$ sample). The $B$. napus actin gene $(B n A C T)$ was used as internal standard

family of proteins suggests that they play many different functional roles in plants, probably acting on a variety of substrates. Specific GDSL lipases have been reported to be involved, for example, in the response to salt stress in $A$. thaliana (Naranjo et al., 2006), or to pathogens in Chinese cabbage (Lee and Cho, 2003). The number of members of the 'classical' lipase gene family is not so high but, still, initial data mining showed the presence of at least 17 gene candidates of the $\mathrm{GxSxG}$ lipase gene family in the Arabidopsis thaliana genome (Beisson et al., 2003), while a more recent analysis increased this number to 38 putative genes (Li et al., 2012). As for the GDSL lipases, the GxSxG lipases may fulfil different biological functions in plants. They may act releasing fatty acids from membrane lipids; fatty acids are important signalling molecules, which participate in the regulation of developmental processes and in the responses of plants to abiotic and biotic stress (Farmer et al., 1998); in agreement with this idea, some lipases have been shown to be induced by pathogens and to be necessary for the activation of defence responses (Falk et al. 1999, Jakab et al. 2003, and references therein).

Apart from the high complexity of the lipase gene families, elucidation of their biological functions is hampered by the fact that their physiological substrates are generally unknown, since for those - relatively few - lipases that have been purified from plants, the enzymatic activity has been demonstrated only in vitro and with artificial, model substrates. Therefore, analysis of the expression patterns of the isolated lipase genes may provide some clues as to their in vivo functions.

The BnLIP gene is transcriptionally activated, specifically, during the early stages of seed germination, but its mRNA accumulates only transiently, so that it is not detected in older seedlings. Moreover, the gen does not seem to be expressed in 
adult plants. These data strongly suggest that the BnLIP protein is one of the lipases responsible for hydrolysis of TAGs stored in rapeseed seeds, as it has been shown for lipases from other species (Eastmond, 2004, 2006). The free fatty acids produced are transported to the glyoxysome, where they undergo $\beta$-oxidation to generate acetyl-CoA, which is finally converted into glucose through the glyoxylate cycle and gluconeogenesis (Hayashi et al., 2002; Eastmond, 2006; and references therein). The synthesized glucose will sustain early seedling growth until the photosynthetic machinery is functional. The expression profile of BnLip is also similar to that of genes involved in the glyoxylate cycle (Beevers, 1979), thus supporting its possible involvement in fat mobilization during seed germination.

Enzymatic assays of $B$. napus cotyledon extracts detected a lipase activity which varied more or less in parallel with the expression of the BnLIP gene: present at very low levels in ungerminated seeds, the activity greatly increased during germination with a maximum at three DAG, to rapidly decrease afterwards (Belguith et al., 2001). The same authors identified a polypeptide of ca. $55 \mathrm{kDa}$ apparent molecular weight in the 3-day-old cotyledon extracts, which cross-reacted, in different immunological assays, with a polyclonal antibody raised against a porcine pancreatic lipase (Belguith et al., 2001). It is possible, therefore, that this activity is encoded by the isolated BnLIP gene. Yet, this must be demonstrated since several lipase genes can be simultaneously expressed in the seedlings; for example, a different rapeseed lipase - with a molecular mass of $38 \mathrm{kDa}$ - has been more recently purified, apparently to homogeneity, from the same cotyledon extracts (Belguith et al., 2013). Production of the recombinant lipase protein and its extensive biochemical and enzymatic characterisation, including the identification of possible physiological substrates, should provide relevant information concerning the biological function of the $B n L I P$ gene during seed germination in B. napus.

\section{References}

Abigor RD, Uadia PO, Foglia TA, Haas MJ, Scott K, Savary BJ (2002). Partial purification and properties of lipase from germinating seeds of Jatropha curcas L. Journal of the American Oil Chemists' Society 79(11):1123-1126.

Akoh CC, Lee GC, Liaw YC, Huang TH, Shaw JF (2004). GDSL family of serine esterases/lipases. Progress in Lipid Research 43:534552.

Barros M, Fleuri LF, Macedo GA (2010). Seed lipases: sources, applications and properties - a review. Brazilian Journal of Chemical Engineering 27:15-29.

Beevers H (1979). Microbodies in higher plants. Annual Review of Plant Physiology 30:159-193.

Beisson F, Koo AJ, RuuskaS, Schwender J, Pollard M, Thelen JJ, .. Ohlrogge JB (2003). Arabidopsis genes involved in acyl lipid metabolism: A 2003 census of the candidates, a study of the distribution of expressed sequence tags in organs, and a web-based database. Plant Physiology 132:681-697.

Belguith H, El Khil HK, Fattouch S, Jridi T, Ben Hamida J (2001). Contribution of botting techniques to the study of rapeseeds (Brassica napus L.) lipases. Electrophoresis 22:18-22.

Belguith H, Fattouch S, Jridi T, Ben Hamida J (2013). Immunopurification and characterization of a rape (Brassica napus L.) seedling lipase. African Journal of Biotechnology 12(21):3224-3234.

Eastmond PJ (2004). Cloning and characterization of the acid lipase from castor beans. Journal of Biological Chemistry 279(44):45540-45545.

Eastmond PJ (2006). SUGAR-DEPENDENT1 encodes a patatin domain triacylglycerol lipase that initiates storage oil breakdown in germinating Arabidopsis seeds. The Plant Cell 18: 665-675.

Enujiugha VN, Thani FA, Sann TM, Abigor RD (2004). Lipase activity in dormant seeds of the African oil vean (Pentaclethra macrophylla Benth). Food Chemistry 88:405-410.

Falk A, Feys BJ, Frost LN, Jones JDG, Daniels MJ, ParkerJE (1999).EDSI, an essential component of $\mathrm{R}$ gene-mediated disease resistance in Arabidopsis has homology to eukaryotic lipases. Proceedings of the National Academy of Sciences USA 96:3292-3297.

Farmer EE, Weber H, Vollenweider S (1998). Fatty acid signalling in Arabidopsis. Planta 206:167-174.

Foresti ML, Ferreira ML (2010). Lipase-catalyzed acidolysis of tripalmitin with capric acid in organic solvent medium: analysis of the effect of experimental conditions through factorial design and analysis of multiple responses. Enzyme and Microbial Technology 46:419-429.

Fuchs C, Vine N, Hills MJ (1996). Purification and characterization of the acid lipase from the endosperm of castor oil seeds Journal of Plant Physiology 149:23-29.

Glaied Ghram I, Belguith H, Messaoudi A, Fattouch S, Vicente O, Ben Hamida J (2013). Amplification of the active site of BnLIP3 gene of Brassica napus L. during germination. African Journal of Biotechnology 12(25):3905-3913.

Gupta R, Gupta N, Rathi P (2004). Bacterial lipases: an overview of production, purification and biochemical properties. Applied Microbiology and Biotechnology 64:763-781.

Hayashi H, Bellis LD, Hayashi Y, Nito K, Kato A, Hayashi M, HaraNishimura I, Nishimura M (2002). Molecular characterization of an Arabidopsis acyl-Coenzyme A synthetase localized on gyoxysomal membranes. Plant Physiology 130:2019-2026.

Jakab G, Manrique A, Zimmerli L, Métraux J-P, Mauch-Mani B (2003). Molecular characterization of a novel lipase-like pathogen-induciblegene family of Arabidopsis. Plant Physiology 132:2230-2239.

Lee K-A, Cho T-J (2003). Characterization of a salicylic acid and pathogeninduced lipase-like gene in Chinese cabbage. Journal of Biochemistry and Molecular Biology 36:433-441.

Li W, Ling H, Zhang F, Yao H, Sun X, Tang K (2012). Analysis of Arabidopsis genes encoding putative class III lipases. Journal of Plant Biochemistry and Biotechnology 21:261-267.

Lin YH, Huang AHC (1984). Purification and initial characterisation of lipase from scutella of corn seedling. Plant Physiology 76:719-722.

Ling H, Zhao J, Zuo K, Qiu C, Yao H, Qin J, Sun X, Tang K. (2006). Isolation and expression analysis of a GDSL-like lipase gene from Brassica napus L. Journal of Biochemistry and Molecular Biology 39:297-303.

Naranjo MA, Forment J, Roldán R, Serrano R, Vicente O (2006). Overexpression of Arabidopsis LTL1, a salt-induced gene encoding a GDSL-motiflipase, increases salt tolerance in yeast and transgenic plants. Plant, Cell andEnvironment 29:1890-1900. 
444

Niu Y, Wu G-Z, Ye R, Lin W-H, Shi Q-M, Xue L-J, .. Xue H-W (2009). Global analysis of gene expression profiles in Brassica napus developing seeds reveals a conserved lipid metabolism regulation with Arabidopsis thaliana. Molecular Plant 2(5):1107-1122.

Ogino H, Hiroshima S, Hirose S, Yasuda M, Ishimi K, Ishikawa H (2004). Cloning, expression and characterization of a lipase gene (lip3) from Pseudomonas aeruginosa LST-03. Molecular Genetics and Genomics 271:189-196.

Ollis DL, Chea E, Cygler M, Dijkstra B, Frolow F, Franken SM, . . . Goldman A (1992). The $\alpha / \beta$ hydrolase fold. Protein Engineering, Design \&Selection 5(3):197-211.

Palacios D, Busto MD, Ortega N (2014). Study of a new spectrophotometric end-point assay for lipase activity determination in aqueous media. LWT - Food Science and Technology 55:536-542.

Pandey A, Benjamin S, Soccol CR, Nigam P, Krieger N, Soccol VT (1999). The realm of microbial lipases in biotechnology. Biotechnology and Applied Biochemistry 29(2):119-131.

Peres Polizelli P, Dell Antonio Facchini F, Cabral H, Bonilla-Rodriguez GO (2008). A new lipase isolated from oleaginous seeds from Pachira aquatica (Bombacaceae). Applied Biochemistry and Biotechnology 150(3):233-242.

Quettier AL, Eastmond PJ (2009). Storage oil hydrolysis during early seedling growth. Plant Physiology and Biochemistry 47:485-490.
Romdhane IBB, Frikha F, Achouri IM, Gargouri A, Belghith H (2012). Gene cloning and molecular characterization of the Talaromyces thermophilus lipase catalyzed efficient hydrolysis and synthesis of esters. Gene 494:112-118.

Sanders TH, PatteeHE(1975). Peanut alkalinelipase. Lipids 10(1):50-54.

Santos KC, Cassimiro DMJ, Avelar MHM, Hirata DB, de Castro HF, Fernández-Lafuente R, Mendes AA (2013). Characterization of the catalytic properties of lipases from plant seeds for the production of concentrated fatty acids from different vegetable oils. Industrial Crops and Products 49:462-470.

Seth S, Chakravorty D, Dubey VK, Patra S (2014). An insight into plant lipase research - challenges encountered. Protein Expression and Purification 95:13-21.

Sharma R, Soni SK, Vohra RM, Gupta LK, Gupta JK (2002). Purification and characterisation of a thermostable alkaline lipase from a new thermophilic Bacillus sp. RSJ-1. Process Biochemistry 37:1075-1084.

Vijayakumar KR, Gowda RL (2012). Temporal expression profiling of lipase during germination and rice caryopsis development. Plant Physiology and Biochemistry 57:245-253.

Woolley P, Peterson SB (eds.) (1994). Lipases - their structure, biochemistry and applications. Cambridge University Press, Cambridge. 